FORMALIZAÇÃO E ECONOMIA POPULAR

SOLIDÁRIA: O MODELO DE PESSOA

JURÍDICA COMO SINTOMA DA

COLONIALIDADE DO PODER

Flávia Almeida Pita ${ }^{1}$

\author{
FORMALIZATION AND POPULAR SOLIDARITY \\ ECONOMICS: THE INDIVIDUAL MODEL LEGAL AS \\ SYMPTOM POWER COLONIALITY
}

RESUMO: A partir do conceito de colonialidade do poder (QUIJANO), apresentam-se reflexões a partir da hipótese de que a imposição de uma personalidade jurídica, estruturada e procedimentalizada segundo os cânones tradicionais do Direito ocidental, aos grupos produtivos da Economia Popular Solidária, é incompatível com seus modos originais de convivência e atuação e, por isso, representa uma via aberta à precarização do trabalho coletivo autogestionário. $O$ texto concentra-se na discussão teórica, permeada pelas observações colhidas em experiências extensionistas desenvolvidas na Incubadora de Iniciativas da Economia Popular e Solidária, programa de extensão da UEFS.

Palavras-chave: Colonialidade do Poder. Economia Popular Solidária. Descolonização Jurídica. Formalização. Trabalho Coletivo Autogestionário.
ABSTRACT: From the concept of coloniality of power (QUIJANO), it presents reflections from the hypothesis that the imposition of a legal personality, structured and proceduralized according to the traditional canons of western Law, to productive groups of the Solidarity and Popular Economy is incompatible with their original ways of living and acting and therefore is a way open to the precariousness of self-managed collective work. The text focuses on the theoretical discussion, permeated by observations made in extension experiences developed in the Incubator of Solidarity and Popular Economy Initiatives, ), extension program of the UEFS.

Keywords: Coloniality of Power. Solidarity and Popular Economy. Decolonization of Law. Formalization. Selfmanaged Collective Work.

\footnotetext{
${ }^{1}$ Professora Assistente do Curso de Direito da Universidade Estadual de Feira de Santana-UEFS (Bahia, Brasil). Mestre em Direito Público pela Universidade Federal de Pernambuco- UFPE. Doutoranda do Programa de Pós-graduação em Sociologia e Direito da Universidade Federal Fluminense-UFF. Integrante da Incubadora de Iniciativas da Economia Popular e Solidária da UEFS - IEPS/UEFS e do Grupo de Estudos e Pesquisas em Economia Popular e Solidária e Desenvolvimento Local Solidário. Procuradora do Estado da Bahia. E-mail: fa-pita@uol.com.br.
} 


\section{INTRODUÇÃO}

O trabalho coletivo, exercido de forma autogestionária, tem sido apontado como um caminho para a construção e fortalecimento de relações econômicas e experiências de produção que contradizem a lógica hegemônica do capitalismo. São traços característicos centrais de tais arranjos econômicos alternativos, não obstante sua heterogeneidade, a organização de coletivos de trabalhadores que têm como pretensão atuar de forma autogestionária, fora da lógica da exploração do trabalho pela apropriação da mais-valia, assumindo como valores centrais a solidariedade (em oposição ao individualismo e competitividade das práticas hegemônicas) e a ressignificação do trabalho como potencializador de uma vivência e uma subjetividade emancipadora e comunitária.

No quadro de crise da sociedade do trabalho (ANTUNES, 2005), o discurso e as práticas da Economia Popular Solidária são por vezes apontadas como consequências e cúmplices dos arranjos do capital na busca de alternativas para a absorção de um volume cada vez maior de trabalhadores que não se adéquam ao modelo do proletariado fabril estável, para o que serve de indício o fato de que os trabalhadores e trabalhadoras deste universo frequentemente enfrentam condições precarizadas de trabalho (insegurança, baixa remuneração, falta de acesso ao sistema de seguridade social etc.). A pesquisa em que se insere o presente texto, visa, em especial, a contribuir para a compreensão e o fortalecimento da Economia Popular Solidária, e mais especificamente, para a dissolução dos laços que mantém ou pode manter com a precarização do trabalho.

Nesse sentido, parece compactuar para tal realidade de precarização o fato de que uma parte considerável das iniciativas da Economia Popular Solidária não chega a 
formalizar-se como uma pessoa jurídica². Há indícios que este percentual seja ainda maior, já que a informalidade, em si, é um obstáculo à identificação dos grupos pelos levantamentos oficiais.

A formalização dos grupos produtivos tem no sistema jurídico seu primeiro e maior obstáculo. O arcabouço jurídico resulta em uma realidade excludente: onerosidade e complexidade da formalização, falta de clareza do sistema tributário, inacessibilidade da burocracia estatal (penetrável tão somente por meio de documentos escritos), profusas exigências procedimentais e contábeis no transcorrer da existência das pessoas jurídicas (contraditoriamente acentuadas no caso das cooperativas, o tipo organizativo, em tese, mais aproximado dos ideais da Economia Popular Solidária). São todos fatores, enfim, que afastam e imobilizam pessoas que compartilham as desvantagens da exclusão econômica e de experiências frustradas de educação formal.

Até o momento pesquisas que vínhamos desenvolvendo junto à Incubadora de Iniciativas da Economia Popular e Solidária da UEFS - IEPS-UEFS ${ }^{3}$, concomitantemente a outros esforços idênticos ${ }^{4}$, voltavam-se à identificação de um formato jurídico mais adequado às iniciativas da economia popular e solidária no Brasil. Constatou-se, então, que os formatos disponíveis - a associação e as sociedades empresárias e simples, entre as quais se destaca a cooperativa - por maiores ou menores razões, de ordem burocrática, tributária, contábil, ou econômica - não respondiam à realidade a que deveriam acolher. A pergunta que se fazia era: qual seria o tipo de pessoa jurídica que melhor atenderia a necessidade de formalização jurídica dos grupos?

\footnotetext{
${ }^{2}$ O último Relatório do Sistema Nacional de Informações em Economia Solidária (SIES), da Secretaria Nacional de Economia Solidária (MTE. SIES, 2013), relativo ao período de 2010-2012, indica que dos 19.708 EES catalogados, 6.018 correspondem a grupos informais (30,5\%). A forma preponderante é a associação (60\%), seguida da Cooperativa (8,8\%). Outras "sociedades mercantis" correspondem a 0,6\% do universo pesquisado.

${ }^{3}$ Programa de Extensão e pesquisa multidisciplinar da Universidade Estadual de Feira de Santana, Bahia, cuja equipe a Autora integra desde 2010. Maiores informações são acessíveis no endereço <http://incubadorauefs.blogspot.com.br/>.

${ }^{4}$ Citam-se como exemplos KRUPPA et al. (2012) e SANCHEZ (2012).
} 
O avançar das pesquisas e o amadurecimento das reflexões começaram, então, a exigir uma perspectiva diversa. A aposta na formalização, mesmo que a partir de um tipo jurídico renovado ou adaptado, passou a ser atravessada por outros questionamentos, estimulados em especial pelas reflexões em torno do conceito de colonialidade do poder (QUIJANO, 1992): ela representaria, de fato, uma mudança no quadro que afasta os grupos da Economia Popular e Solidária do reconhecimento jurídico? Não seria esta via ainda presidida por uma lógica estrangeira às experiências que se deseja tutelar, impregnada por valores e estruturas pertencentes a uma rede de sentidos (SOMBRA, 2015) imposta aos povos colonizados sob a lógica da racionalidade moderna de origem europeia, produzida a partir do processo de divisão do trabalho imposto pelo capitalismo mundial?

A hipótese que se está formular - e este texto reflete tão somente o início deste processo - aponta, assim, para um sentido ainda não explorado. No lugar da busca por um tipo jurídico mais adequado à formalização dos coletivos de trabalhadores da Economia Popular Solidária, passa-se a entender que o desafio seja a adaptação do ordenamento brasileiro para o reconhecimento das relações jurídicas travadas por eles, sem que se constituam como pessoas jurídicas. Em outras palavras, o reconhecimento de sua condição de sujeitos de direito coletivos, sem que seja necessária a formalização, no sentido assumido pela tradição jurídica eurocentrada, ressignificando-se a própria categoria da informalidade.

No seu horizonte mais distante, a pesquisa visa a encontrar resposta para a seguinte questão: seria viável o redirecionamento da luta política no campo da normatividade estatal em direção à construção de um arcabouço jurídico que acolha e reconheça os grupos em sua original formação?

Supondo-se, então, a afirmativa - e partindo-se da convicção de que produzir conhecimento só se justifica se tem como horizonte próximo a transformação desintegradora dos processos de empobrecimento, da exploração e da opressão -, pretende-se igualmente, a partir da observação de experiências reais, imaginar e propor 
elementos para a arquitetura jurídica dessa via alternativa, capazes de desvincular, ou minimizar, a ausência de forma jurídica tradicional da precarização dos coletivos autogestionários de trabalhadores.

A pesquisa projetada tem como primeira premissa metodológica a compreensão de que, não importa o tipo de conhecimento científico, o cientista não se aparta de seu objeto de estudo (não há espaços vazios entre "sujeito" e “objeto"), por que não se aparta do mundo que constrói a partir da linguagem, não sendo mesmo possíveis o "descompromisso", a "ordem", a "estabilidade", tão caras ao conceito tradicional de ciência. Assim, acredita-se que todo conhecimento científico-natural é científico social, todo conhecimento é local, é autoconhecimento e visa constituir-se em senso comum senso comum com o qual os seres humanos dão sentido às suas vidas (SANTOS, 2010, p. 88).

Em seguida, o olhar que se lança sobre a realidade pesquisada objetiva identificar os múltiplos fatores que para ela contribuem, considerando que toda formação social é contraditória, dinâmica e histórica, e - não obstante a sua totalidade não possa ser abarcada de forma categórica e objetiva, nos moldes cartesianos de ciência - que a observação da realidade, a partir das categorias teóricas propostas (Economia Popular Solidária, descolonização jurídica, formalização, em especial), pode conduzir à síntese de um novo caminho. Ademais, para a pesquisadora, a compreensão da realidade não se constitui em um objetivo em si, mas declaradamente uma via para produzir mudanças, para contribuir na construção de relações humanas mais equânimes.

Neste texto, em específico, apresentam-se reflexões inicias acerca da colonialidade do poder (QUIJANO, 1992) e de sua apropriação pela instância sócio-jurídica, por meio do da ideia de descolonização jurídica, bem como se inicia a leitura do problema da formalização jurídica dos grupos produtivos da Economia Popular Solidária sob o filtro deste referencial teórico. 


\section{COLONIALIDADE DO PODER E DESCOLONIZAÇÃO JURÍDICA}

O conceito de colonialidade do poder, desenvolvido originalmente pelo sociólogo peruano Aníbal Quijano (1992), desvela a permanência da relação de dependência mantida entre a Europa e os povos por ela colonizados - especialmente na America Latina -, de um modo que vai muito além das relações de subserviência econômica: sob perspectiva sobretudo epstemológica, a configuração dos sentidos que ordenam a compreensão do mundo, das subjetividades, das relações, do conhecimento, do trabalho, mantém-se regida sob a lógica construída e disseminada, desde o final do século XV, pela visão de mundo naturalizada pelos colonizadores europeus, legitimada pela estratificação a partir da noção de raça.

Tal processo, concomitante à consolidação do capitalismo, implicou, segundo Quijano (2005) na artificial construção histórica das realidades não europeias sob a lógica da onipresente relação capital-trabalho fabril, nos moldes do capitalismo industrial que paulatinamente se consolidava, mas sem a necessária correlação real com o que acontecia, especialmente fora da Europa (QUIJANO, 2013, p. 151):

Sin embargo, si existen 200 millones de esclavos, si la servidumbre personal está de regreso, si la pequeña producción mercantil es ubicua mundialmente, ya que es el elemento central de lo que se denomina "economía informal", si la reciprocidad, es decir, el intercambio de trabajo y fuerza de trabajo que no pasa por el mercado, están en proceso de re-expansión, entonces tenernos la obligación teórica e histórica de preguntarnos, si por lo tanto hay algo que no habíamos visto bien en esta idea de que el capitalismo generaba tal único patrón de clasificación social y creo que la conclusión es inevitable: esta idea era básicamente errónea porque nunca ocurrió así y porque, con toda probabilidad, nunca ocurrirá así. Y creo que América Latina es un excelente ejemplo para mostrar que así no fue nunca.

Há que se ressaltar que o pensamento de Quijano pode ser associado a todo um quadro teórico que tem recebido diferentes denominações e enfoques - estudos culturais, pós-coloniais, subalternos, decoloniais,- mas que se encontra na coincidência de uma postura crítica perante a racionalidade moderna eurocentrada. Não se trata, portanto, de uma voz isolada: 
O projeto pós-colonial é aquele que, ao identificar a relação antagônica entre colonizador e colonizando, busca denunciar as diferentes formas de dominação e opressão dos povos. Como uma escola de pensamento, o pós-colonialismo não tem uma matriz teórica única, sendo associado aos trabalhos de teóricos como Franz Fanon, Albert Memmi, Aimé Césaire, Edward Said, Stuart Hall e ao Grupo de Estudos Subalternos, criado na década de 1970 pelo indiano Ranajit Guha (ROSEVICS, 2014).

Aníbal Quijano assume para a pesquisa, no entanto, relavância de destaque na medida em que se preocupa em apontar a vinculação entre colonialidade do poder e um projeto de capitalismo mundial, associado a uma estrutura global de controle do trabalho, baseada nas relações que se contruíram no processo de colonização a partir da divisão racial:

O controle do trabalho no novo padrão de poder mundial constituiu-se, assim, articulando todas as formas históricas de controle do trabalho em torno da relação capital-trabalho assalariado, e desse modo sob o domínio desta. Mas tal articulação foi constitutivamente colonial, pois se baseou, primeiro, na adscrição de todas as formas de trabalho não remunerado às raças colonizadas, originalmente índios, negros e de modo mais complexo, os mestiços, na América e mais tarde às demais raças colonizadas no resto do mundo, oliváceos e amarelos. $\mathrm{E}$, segundo, na adscrição do trabalho pago, assalariado, à raça colonizadora, os brancos.

Essa colonialidade do controle do trabalho determinou a distribuição geográfica de cada uma das formas integradas no capitalismo mundial. Em outras palavras, determinou a geografia social do capitalismo: o capital, na relação social de controle do trabalho assalariado, era o eixo em torno do qual se articulavam todas as demais formas de controle do trabalho, de seus recursos e de seus produtos (QUIJANO, 2005, p. 120).

Se tomarmos o Direito - ou, como prefere Michel Miaille, a instância jurídica como um "sistema de comunicação formulado em termos de normas para permitir a realização de um sistema determinado de produção e de trocas econômicas e sociais" (MIAILLE, 2005, p. 96), intui-se a importância política da tarefa de compreender como se disciplinam os encontros/desencontros de diferentes esferas de interesse, produzem-se formas para conviver, transformar ou resolver os conflitos que refletem um universo simbólico diverso do que foi naturalizado como produto da razão humana nas estruturas 
jurídicas presentes no Direito ocidental capitalista - e acolhidas, no dizer de Boaventura de Souza Santos (2007), pelos povos situados ao sul da linha abissal, irmanados no mesmo passado colonial, na herança de um conhecimento produzido de modo a separar visíveis de invisíveis, e em uma estrutura jurídica correspondente, que reproduz uma lógica exterior, a legitimar a exclusão:

\begin{abstract}
Durante el transcurso de la colonización de las naciones latinoamericanas, predominó la reproducción eurocéntrica de una cultura de derecho filosófico y un aparato jurídico impuesto por el poder hegemónico de las Metrópolis.[...]

Consecuentemente, el escenario histórico de la cultura jurídica como producto de la actividad humana y espacio legitimado para reflexionar sobre la justicia, las normas de conducta y los valores jurídicos esenciales acabó prestándose a legitimar formas conceptuales abstractas, manifestaciones institucionales disociadas de praxis social y exaltación erudita de codificaciones importadas de las metrópolis. (WOLKMER, 2012)
\end{abstract}

É, assim, sob a perspectiva da descolonização ${ }^{5}$ que se deseja pensar as experiências de trabalho coletivo que vêm sendo reunidas sob a expressão Economia Popular Solidária.

\title{
3 ECONOMIA POPULAR SOLIDÁRIA
}

Economia Social, Alternativa, Invisível, Subalterna, Periférica, Solidária, Economia Popular Solidária ${ }^{6}$ : dentre as diversas denominações para ela utilizadas, a versão escolhida intenta agregar às notas distintivas do que se vem denominando de Economia Solidária "atividades econômicas organizadas segundo princípios de cooperação, autonomia e gestão democrática" (LAVILLE; GAIGER, 2009, p. 162) - o caráter de uma economia política dos setores populares (LIMA, 2014, p. 74,) Economia Popular e Solidária, neste sentido

[...] trata-se de uma expressão que demarca uma passagem de transição organizativa, por vezes vinda de economia popular, bem como pela representatividade epistemológica forjada na América Latina[...].

\footnotetext{
${ }^{5}$ Não obstante aqui se opte pelo termo "descolonial", é corrente o uso de "decolonial”. Segundo Larissa Rosevics (2014), o termo "decolonial" é proposto por Walter Mignolo, "para diferenciar os propósitos do Grupo Modernidade/Colonialidade e da luta por descolonização do pós-Guerra Fria, bem como dos estudos pós-coloniais asiáticos."

${ }^{6}$ Uma boa retrospectiva sobre a gênese e utilização das diversas expressões, no Brasil e fora dele, em LECHAT (2002)
} 
Atua, de maneira geral, descontratualizada, sob o protagonismo popular que se manifesta em trabalhos familiares e coletivos, pela escolha por atividades autônomas ou por não se adequar ao modelo mercadológico vigente ou, ainda, por opção consciente em relação a outro modelo socioprodutivo (LIMA, 2014, p. 73).

Pondo de lado neste espaço discussões quanto ao grau de fechamento sistemático ${ }^{7}$ e a concretização efetiva de seus princípios e objetivos, é certo que, no Brasil, a Economia Popular Solidária traduz-se em números expressivos ${ }^{8}$, tendo sido catalogados, segundo o último mapeamento realizado pela então Secretaria de Economia Solidária - SENAES $(2013)^{9}$, cerca de 1.500 .000 trabalhadores e trabalhadoras, em cerca de 20.000 iniciativas $\left(\mathrm{EES}^{10}\right)$.

Mesmo sendo necessárias e pertinentes as críticas a uma aproximação romântica e utópica do universo da Economia Popular Solidária, entende-se, igualmente, que ela pode ser uma efetiva via para o nebuloso caminho "para além do capital" - apta a gerar "no seio mesmo da velha sociedade", "as condições materiais de existência" de "novas relações de produção mais adiantadas" (MARX, 1982, p. 26) - desde que correlacionada a um projeto político de luta social, capaz de contribuir, processualmente, para o que Ricardo Antunes (2005, p. 92) chama de "condições sociais para o florescimento de uma subjetividade autêntica e emancipada, dando um novo sentido ao trabalho".

\footnotetext{
${ }^{7}$ Como tentar responder se a Economia Solidária corresponderia a um modo de produção alternativo ao capitalismo, por exemplo, como afirma Paul SINGER (2002). Para essa discussão remete-se a SCHMIDT (2013).

${ }^{8}$ Remete-se à obra Produzir para Viver: os caminhos da produção não capitalista, organizada por Boaventura de Souza Santos (2005), representativa da multiplicidade e factualidade de tais experiências no resto do mundo.

${ }^{9}$ A Reforma Ministerial Federal anunciada em 02 de outubro de 2015 promoveu a fusão entre o Ministério da Previdência e o Ministério do Trabalho e Emprego, criando o novo Ministério do Trabalho da Previdência Social. Não é conhecido, até o momento, o destino da antiga Secretaria de Economia Solidária.

${ }^{10}$ Nomeados no levantamento oficial pela sigla EES, empreendimentos de economia solidária. Prefere-se, no entanto, evitar se o uso da palavra empreendimento, pela sua relação semântica com o contexto da organização capitaltrabalho nos moldes capitalistas, contraditório, em tese, a nosso ver, com Economia Popular Solidária. Utilizar-se-á a sigla EES, assim, somente quando inevitável.
} 
Nesse passo, reconhecendo as contradições e obstáculos inerentes a tais experiências, e o risco de compactuarem com um cenário de precarização do trabalho ${ }^{11}$, identifica-se nelas também potencial transformador, desde que construídas na perspectiva da luta de classes, do fortalecimento político de redes, "constituindo no imaginário coletivo a consciência da possibilidade da autogestão, desenvolvendo tecnologias alternativas às do capital adaptadas à autogestão plena e respeitadora do meio ambiente" (SCHMIDT, 2013, p. 26).

Na esteira dos três primeiros Fóruns Sociais Mundiais, ocorridos entre 2001 e 2003 em Porto Alegre, e da criação simultânea, em 2003, do Fórum Brasileiro de Economia Solidária, da SENAES e do Conselho Nacional de Economia Solidária, em 2006, são constatáveis, no Brasil, avanços na conformação de um aparato normativo e burocrático de suporte às iniciativas da Economia Popular Solidária.

Ainda se ressalta, todavia, que entre as "fraquezas da economia solidária que precisam ser superadas", a ausência de um marco legal de fato responsivo a tal realidade é questão diversas vezes tangenciada pelo 1ㅇ Plano Nacional de Economia Solidária - 20152019, produto da 3ạ Conferência Nacional de Economia Solidária:

- Ausência de um marco legal da economia solidária que garanta o devido reconhecimento dos empreendimentos econômicos solidários, [...]

- Inexistência de uma figura jurídica de Empreendimento Econômico Solidário (EES), garantindo uma regulamentação e tributação adequadas à realidade dos EES, respeitando suas especificidades, e assegurando seu acesso aos direitos da previdência social;[...]

- Dificuldade de acesso à formalização dos empreendimentos econômicos solidários, sobretudo para aqueles que optam pela forma cooperativa, tendo em vista as barreiras legais de registro, os custos de manutenção e as obrigações

\footnotetext{
${ }^{11}$ Partindo-se de um quadro multifatorial embalado pela crise do petróleo, esgotamento do modelo fordistakeynesiano e sua gradual substituição pela lógica toyotista, desregulação cambial e financeira imposta pelos Estados Unidos e consequente globalização financeira, desenvolvimento acentuado das tecnologias de informação e comunicação, o mundo entra, a partir dos anos 70, em um período de grandes mudanças do mundo do trabalho, em que se destaca fortemente a ideia de precarização da condição do trabalhador: aumento do desemprego e da pobreza, alargamento do setor terciário, do trabalho temporário, parcial, subcontratado, terceirizado, heterogeneização da classe trabalhadora, baixa remuneração e precária inserção nos sistemas de seguridade social, intensificação do trabalho, flexibilização do trabalho, retraimento da organização sindical (PASTORINI, 2004).
} 
fiscais que asfixiam aquelas iniciativas desde a sua origem (CONAES, 2014, p. 1112).

Adicione-se que, mesmo considerando a produção legislativa que já se tem, a distância entre a direção apontada por tais normas, e a concretização de um aparato jurídico que, de fato, seja capaz de refletir as necessidades e a realidade das iniciativas de Economia Solidária no Brasil, ainda é muito grande. A própria SENAES reconhece, em balanço de sua atuação entre 2003 e 2010, que, quanto ao marco jurídico, "do ponto de vista do reconhecimento, da formalização e do tratamento tributário adequado aos EES, a atual legislação está ultrapassada e reduz experiências variadas de ES a determinadas formas legais que não consideram nem reconhecem a diversidade das organizações, além de impedir, na prática, o funcionamento de algumas delas" (SENAES/MTE, 2012, p. 44). Os avanços, assim, apontam para um destino sem a correspondente construção de uma via concreta para alcançá-lo, num bom exemplo do "fosso entre o excesso de sentido e o défice de desempenho", de que fala Boaventura de Souza Santos (2003, p. 40).

O que se quer, então, é investigar caminhos para a superação do citado défice, situando-o sob o prisma da colonialidade, que impregna também o Direito, para pensar o problema específico da formalização das iniciativas de Economia Popular Solidária.

\section{O PROBLEMA DA FORMALIZAÇÃO JURÍDICA DE INICIATIVAS DA ECONOMIA POPULAR SOLIDÁRIA}

A questão da forma jurídica para os grupos que atuam sob a lógica da Economia Popular Solidária no Brasil é especialmente ressaltada a partir dos mapeamentos realizados pela SENAES, concluídos em 2007 (2005-2007) e em 2013 (2010-2013), que tornaram possível uma visão panorâmica dos tipos jurídicos mais utilizados na realidade das iniciativas. Particularmente a partir desses dados, podem ser identificadas investigações ao derredor das tipologias jurídicas adotadas pelos grupos de Economia Popular e Solidária no Brasil e das discussões voltadas à formulação do marco legal 
brasileiro para essa outra Economia, de uma forma geral apontando-se para a necessidade de adaptação legal da sociedade cooperativa à realidade própria aos grupos populares da Economia Solidária, diante da constatação de que os tipos jurídicos existentes não respondem adequadamente às suas características.

As discussões em torno do marco legal para a Economia Popular Solidária parecem continuar, no entanto, desenvolvendo-se a partir de conceitos e estruturas jurídicas correspondentes a uma tradição que, desconsiderando a realidade vivenciada pelos grupos, volta-se para modelos que estão a exigir um esforço descolonizador.

A lógica que dá suporte à discussão da informalidade dos grupos (calcada em noções como contrato, direito subjetivo individual, separação patrimonial, responsabilidade patrimonial) são heranças de uma tradição jurídica que, como todo o resto, reproduz parâmetros estranhos à história, experiências e realidade da maior parte da população latino-americana, impostos pelo processo colonizatório que, até hoje, deixa marcas e reproduz desigualdades em nossa realidade.

Segundo Vicente Ráo (1997, pp. 73-734), a noção de ente coletivo titular de capacidade jurídica, remonta a Roma, e se desenvolve a partir de então, agregando elementos do direito germânico (na prática da propriedade de mão comum Gessamtehand) e do direito canônico, "que ampliou o conceito de instituição, atribuindo este caráter a todos os entes eclesiásticos [...], ou ofícios dotados de patrimônio e às fundações". Nota-se, desde já, a força que a propriedade privada assume para o conceito, o que parece se recrudescer mais adiante, na medida em que a personificação jurídica assume um papel importante para o desenvolvimento do capitalismo com as companhias ultramarinas e, já no século XIX, com o desenvolvimento teórico da noção de sociedade comercial, com preponderância da função de separação do patrimônio dos sócios do da sociedade, mantendo-se aqueles a salvo dos riscos da atividade empresarial. Fabio Conder Comparato (1977 apud SILVA, 2002, p. 67) chega a concluir que “a personificação 
societária corresponderia - senão juridicamente, ao menos econômica e filosoficamente a uma modalidade especial de exercício do direito de propriedade".

Por outro lado, as estruturas jurídicas previstas para os sujeitos de direito coletivos (mesmo, em certa medida, para a sociedade cooperativa) correspondem a uma estrutura hierarquizada de poder, reprodutoras de modelos que, desde o Estado, parecem ser reconhecíveis nos arranjos sociais característicos das sociedades burguesas patriarcais. Observe-se, neste sentido, o conceito weberiano de associação:

O termo "associação" está reservado a uma relação social que é fechada para estranhos ou restringe sua admissão por regulamentos, e cuja autoridade é imposta pelas ações de indivíduos especificamente encarregados desta função, como, por exemplo, um dirigente ou chefe, geralmente incluindo um quadro administrativo. Estes funcionários normalmente também exercerão poderes plenos. A incumbência de uma posição executiva ou a participação nas funções do quadro administrativo constituirão a "autoridade governante" e poderão ser apropriados ou delegados de acordo com as regras obrigatórias da associação, estabelecidas em critérios ou procedimentos específicos (WEBER, 2005, p. 87).

De forma muito diversa, na realidade dos coletivos de trabalhadores da Economia Popular Solidária, não é a propriedade comum, de regra, um elemento estruturador fundamental $^{12}$ : na maior parte dos casos ela não existe, sendo a comunhão do trabalho, ou de uma herança cultural (como nos casos das comunidades tradicionais), os motivos que parecem justificar a reunião das pessoas.

Predominam, por outro lado, a mudança, a adaptabilidade aos desafios rotineiros, a rotatividade dos membros (que entram e saem ao sabor dos filhos gerados, do doente a exigir cuidados, da oportunidade de um trabalho temporário, de escolhas que precisam ser feitas). A vida, enfim, aponta no sentido diferente da permanência que fazem supor as exigências burocráticas para a constituição, modificação e extinção de uma pessoa jurídica.

\footnotetext{
${ }^{12}$ Não obstante, em alguns casos, o seja: é o caso, por exemplo, das chamadas comunidades de fecho e fundo de pasto do sertão baiano.
} 
Os modelos hierarquizados, por sua vez, constituem, em si, um obstáculos estrutural e cultural ao ideal de autogestão ${ }^{13}$ que norteia a Economia Popular Solidária:

Os regramentos da autogestão, que seriam os substitutos da hierarquia vigente no mundo capitalista, estão ainda em construção. A propriedade coletiva, ou associada, não está ainda incorporada à cultura, sobretudo quando se trata dos empreendimentos mais recentemente constituídos, como os que são normalmente incubados. As especializações segundo o talento, que foi um dos motores do desenvolvimento capitalista, ainda não foram substituídos por modelos de saber interdisciplinares e é mais difícil definir, nos EES, o papel de cada membro e o alcance e os limites de suas responsabilidades. O que se observa, nos ambientes de muitos EES que ainda não encontraram seus caminhos, é uma confusão de papéis por não haver definições sobre o que fazer em cada caso, como existe no quadro lógico da hierarquia (NUNES, 2009, p. 207).

Parece justificável acreditar, por fim, que, não importam quais sejam as características assumidas pela pessoa jurídica - mesmo considerando-se um renovado tipo societário ou associativo, mais adaptado às demandas da Economia Popular Solidária - a formalização nos moldes hoje praticados provavelmente continuará sendo um obstáculo na realidade brasileira de exclusão e de diversidade. A opacidade, que é marca do fenômeno jurídico tal qual o conhecemos (CÁRCOVA, 1998), e só é suplantada pelo acesso, caro e tortuoso, ao profissional com conhecimento especializado (o advogado, o contador). Quaisquer sejam as características de uma possível nova sociedade cooperativa, ela possivelmente representará pouca mudança para grupos saídos das camadas populares, a quem faltam dinheiro, informação, capacidade de compreensão de

\footnotetext{
${ }^{13}$ Toma-se o sentido de autogestão que não se basta no aspecto estritamente procedimental da tomada de decisões, mas, no dizer de Maurício Sardá de Faria, atenta para o "seu conteúdo utópico e o seu potencial anticapitalista", sendo seu desafio "romper o isolamento e estender-se formando novas redes de intercâmbio para a produção material, colocando em causa o mercado concorrencial capitalista" (2011, p. 279-303). Autogestão, no sentido assumido pela pesquisadora, pressupõe, assim, um processo educativo para o protagonismo consciente e ativo de indivíduos autônomos, que, transpondo os limites da unidade produtiva, carrega em potência a possibilidade de uma "autoinstitucionalização de uma nova realidade social" (FARIA, 2011, p. 304), democratizada no sentido mais radical.
} 
documentos escritos, e mesmo acesso geográfico, considerando que muitos desses grupos encontram-se na zona rural ou nas periferias das cidades ${ }^{14}$.

Simultaneamente, contudo, o suporte jurídico das relações que são travadas no interior dos grupos produtivos da Economia Popular Solidária, e entre os grupos e terceiros, é de grande importância para a sua sobrevivência e consolidação. A chancela do jurídico, além do seu sentido de reconhecimento e autorrespeito (HONNETH, 2009), é especialmente importante também porque a organização dos grupos em redes (MANCE, 1999), ou em "sistemas produtivos integrados" (BENINI; BENINI, 2013) é estratégia fundamental para que a Economia Popular e Solidária seja capaz de representar uma via efetiva de superação do mercado nos moldes capitalistas. Sem a possibilidade de chancela jurídica das relações mantidas pelo grupo, enquanto grupo ${ }^{15}$, este enfrentará obstáculos, muitas vezes intransponíveis, ao escoamento da produção e ao acesso a crédito, que redundam em irregularidade fiscal, práticas sonegatórias e em subterfúgios fomentadores de insegurança e precariedade (ausência de controle contábil das receitas e despesas e consequente falta de transparência, descompromisso com a cobertura previdenciária dos trabalhadores e de outros mecanismos protetivos, a exemplo do Fundo de Garantia por Tempo de Serviço).

A hipótese que inspira a pesquisa representa um giro de perspectiva que não pode ser considerado completamente exótico, sendo possível identificar, na configuração jurídica do sistema brasileiro, indícios de sua viabilidade.

Em primeiro lugar, muito embora "a existência legal das pessoas jurídicas de direito privado" comece, no Direito brasileiro, "com a inscrição do ato constitutivo no respectivo registro" (conforme art. 45 do Código Civil-CC), as sociedades informais não estão

\footnotetext{
${ }^{14}$ Conforme os dados do último levantamento da SENAES (2013), 55\% dos EES são rurais, 10,5\% têm atividades urbanas e rurais e apenas $34,5 \%$ são urbanos.

${ }^{15}$ É comum, por exemplo, a desconsideração do grupo para a solução de problemas decorrentes da informalidade da pessoa jurídica, tais como o cadastramento dos trabalhadores como microempresários individuais, que passam a usar seus números de inscrição no CNPJ para representar as relações mantidas, em verdade, coletivamente.
} 
exatamente à margem da legalidade, já que o mesmo CC disciplina as chamadas sociedades não personificadas (sociedade em comum e a sociedade em conta de participação), admitindo a possibilidade de que travem licitamente relações jurídicas, já que estabelece regras para, por exemplo, a atribuição de responsabilidade pelas obrigações da sociedade (arts. 986 a 996 do Código Civil Brasileiro).

Destaca-se, em seguida, a possibilidade, prevista em alguns programas federais, do estabelecimento de relações jurídicas entre o Estado e grupos não personificados. É exemplo a Lei Federal n. 11.947/2009 que, ao disciplinar o Programa Nacional de Alimentação Escolar - PNAE, previu a obrigatoriedade de destinação de parte (30\%) dos recursos do Fundo Nacional de Desenvolvimento da Educação - FNDE "para a aquisição de gêneros alimentícios diretamente da agricultura familiar e do empreendedor familiar rural ou de suas organizações, priorizando-se os assentamentos da reforma agrária, as comunidades tradicionais indígenas e comunidades quilombolas". A despeito de uma "comunidade tradicional indígena", ou um grupo de agricultura familiar não se constituírem necessariamente no formato de uma pessoa jurídica, a regulamentação da Lei n. 11.947/2009, principalmente no âmbito dos Estados, tem rendido experiências inovadoras, que chancelam a contratação, pelo Poder Público, de grupos informais.

Quando o que se tem em vista é a consolidação dos grupos enquanto produtores e/ou comerciantes de bens e serviços, é patente que a formalização é uma função, em especial, da necessidade de regularização fiscal. É, aliás, a questão tributária essencial para as discussões que envolvem a personalidade jurídica de grupos: é a maior ou menor onerosidade tributária um dos critérios centrais para a escolha do tipo ideal em cada caso. Na maior parte das vezes, aliás, a formalização tem, para o grupo, como razão imediata única, tornar possível a inscrição no Cadastro Nacional de Pessoas Jurídicas- CNPJ, que 
compreende "as informações cadastrais das entidades de interesse das administrações tributárias da União, dos Estados, do Distrito Federal e dos Municípios” ${ }^{16}$.

O que se observa, no entanto, é que no CNPJ já hoje se prevê a inscrição de pessoas apenas equiparadas às pessoas jurídicas "pela legislação do Imposto sobre a Renda", (art. 3o da IN RFB n. 1.470/2014), como o empresário individual e outras figuras a que o Direito brasileiro não atribui personalidade jurídica, a exemplo de órgãos públicos que correspondam a unidades gestoras de orçamento, condomínios edilícios, candidatos a cargo político eletivo, entre diversos outros (art. 4음 da IN RFB n. 1.470/2014).

O delineamento de estratégias jurídicas que reflitam e acolham as características do trabalho coletivo autogestionário das camadas populares é, por certo, tarefa desafiadora e que está a exigir esforços de pesquisa. Desde já supõe-se que tal tarefa envolva, entre suas dificuldades, a necessidade de ter em conta: i) a proteção contra a precarização dos direitos dos trabalhadores coletivos, em suas relações internas e externas; ii) proteção das relações jurídicas travadas pelos grupos, considerando-se especialmente a posição do Estado, e a tendência de que arranjos alternativos e benefícios fiscais sejam apropriados por práticas que inversamente legitimem a precarização ${ }^{17}$ ou aproveitados para fins de sonegação, por via da simulação ${ }^{18}$; iii) garantia de acessibilidade pelos grupos (linguagem, acesso geográfico, custo etc.) aos procedimentos de controle burocráticos minimamente necessários.

\footnotetext{
${ }^{16}$ Conforme art. 2o da Instrução Normativa RFB n. 1.470, de 30.05.2014.

${ }^{17}$ Representadas pelo denominado "discurso empreendedor", impregnado nas políticas públicas apoiadoras do microempreendedorismo individual, apresentado como via de solução à informalidade. A "pejotização" do trabalhador informal tem representado, no entanto, a chancela a práticas fraudulentas de terceirização, fadadas a escamotear relações de trabalho subordinadas, ou, mesmo que isto não se dê literalmente, compactuado com um discurso naturalizador da exclusão social, que disfarça sua origem no sistema de produção de mercadorias, para transformá-la, "tanto sob o ponto de vista objetivo (econômica) quanto subjetivo (político-ideológica)", no "verdadeiro mote que garante o bom funcionamento do sistema (ALVIM; NUNES; CASTRO, 2013, p. 15)

${ }^{18}$ É o caso de regimes diferenciados de tributação para pequenas empresas, a exemplo do Simples Nacional (Lei Comp. 123/2006), que "também têm 'estimulado' a utilização de simulação: pessoas jurídicas com faturamento incompatível com a definição de pequena empresa são pulverizadas em "pequenas" empresas, beneficiárias do regime fiscal menos oneroso, mas que continuam tendo como verdadeiros destinatários do respectivo proveito econômico as mesmas pessoas vinculadas à grande empresa 'cindida'”. (PITA, 2009, p.135-136)
} 
Enfim, antes estávamos em busca de uma nova "roupa" para os grupos da Economia Popular e Solidária, porque nenhuma das vestimentas disponíveis se ajustava às suas realidades (PITA, 2015). O melhor não seria, no lugar disso, reconhecer a sua nudez original, como capaz de responder à forma como se relacionam, adaptados tradicionalmente ao "clima" sob o qual, desde sempre, exerceram seu trabalho e seus vínculos? Com a mudança de perspectiva, começa-se a cogitar que, talvez, o melhor seria que se alterassem as regras para o ingresso na "festa", de modo que o convite deixe de lado as exigências quanto ao traje...

\section{CONCLUSÃO}

A investigação está, como se expôs, em seu início, sendo o objetivo deste texto tão somente expor os elementos utilizados para identificação e delimitação do problema, posicionando-o diante das referências teóricas escolhidas.

Uma analogia parece cair bem como ponto final, ilustrando a ideia em concepção. Até os anos 80 era o casamento civil, heterossexual, monogâmico e vitalício (somente em 1977 o divórcio passa a ser possível no Brasil) a única forma de garantir a proteção de direitos resultantes da convivência estável de duas pessoas no Brasil. Ele parece, no entanto, nunca ter efetivamente correspondido majoritariamente às práticas e vínculos reais entre as pessoas de "carne e osso". Após um longo e batalhado percurso de enfrentamentos políticos e jurídicos, somente com a Constituição de 1988 o casamento "informal" (a chamada união estável) foi reconhecido como fonte legítima de direitos, em pé de igualdade com o casamento civil. Nos últimos anos, o mesmo fenômeno alcança as uniões homossexuais, e já se tem notícia de casos em que se reconhecem direitos decorrentes de situações de poligamia (como alimentos ou pensão por morte às "amantes"). Por que não pensar o problema da informalidade dos coletivos de trabalhadores sob a mesma lógica? 
A decisão pela formalização jurídica de grupos produtivos, e o processo que a antecede, aliás, reproduzem dilemas muito semelhantes aos dos noivos. Interessante, neste sentido, é destacar como a palavra "medo" foi muitas vezes ouvida em rodas de conversa realizadas durante experiências de incubação desenvolvidas pela IEPS-UEFS, nos momentos que antecedem a formalização. Causam medo, de fato, a estabilidade, a permanência, a definitividade que são próprias da lógica de um mundo que se descreve como perfeito, como racional, mas cuja racionalidade, importada e imposta de fora para dentro, é negada nas práticas e vivências cotidianas.

\section{口a}

\section{REFERÊNCIAS}

ANTUNES, Ricardo. O caracol e sua concha: ensaios sobre a nova morfologia do trabalho. São Paulo: Boitempo, 2005.

BENINI, Elcio Gustavo. BENINI, Edi Augusto. A economia solidária nos prismas marxistas: revolução ou mitigação? In: SCHMIDT, Carlos; NOVAES, Henrique T. Economia solidária e transformação social: rumo a uma sociedade para além do capital? Porto Alegre: Editora da UFRGS, 2013, p. 55-76.

BRASIL. Instrução Normativa RFB n. 1.470, de 30.05.2014 Disponível em: http://normas.receita.fazenda.gov.br/sijut2consulta/link.action?idAto=52901\&visao=anot ado. Acesso em: 12/07/2015.

BRASIL. Lei Federal n. 10.406, de 10.01.2002 (Código Civil Brasileiro) Disponível em: http://www.planalto.gov.br/ccivil_03/leis/2002/L10406.htm. Acesso em: 12/07/2015.

CÁRCOVA, Carlos María. A opacidade do direito. São Paulo: LTr, 1998.

CASTRO, Carla Appollinario de. ALVIM, Joaquim Leonel de Rezende. Nunes, Tiago de Garcia. Cidadania no Brasil e (nova) questão social: alguns elementos para problematizar uma relação. Sociedade em Debate, Pelotas, n. 19, v. 1, p. 61-86, jan.-jun/2014.

CONAES - Conselho Nacional de Economia Solidária. 10 Plano Nacional de Economia Solidária $\quad$ - $\quad 2015-2019.2014 .20$ Disponível http://www.mte.gov.br/images/Documentos/EconomiaSolidaria/PlanoNacional.pdf. Acesso em: 15/03/2015. 
FARIA, Maurício Sardá de. Autogestão, cooperativa, economia solidária: avatares do trabalho e do capital. Florianópolis: Editoria em Debate - UFSC, 2011.

HONNETH, Axel. Luta por reconhecimento: a gramática moral dos conflitos sociais. 2. ed. São Paulo: Ed. 34, 2009.

KRUPPA, Sonia Maria Portella et al. Regime jurídico das cooperativas populares e empreendimentos em economia solidária. Série Pensando o Direito, vol. 46. Brasília: Ministério da Justiça, 2012.

LAVILLE, Jean-Louis; GAIGER, Luiz Inácio. Economia Solidária. In: CATTANI, Antonio David. et al. Dicionário internacional da outra economia. Coimbra: Almeida, 2009. p. 162-168.

LECHAT, Noëlle Marie Paule. As raízes históricas da economia solidária e seu aparecimento no Brasil. Palestra proferida na Unicamp por ocasião do II Seminário de Incubadoras Tecnológicas de Cooperativas Populares, em 20 mar 2002. Disponível em: http://www.itcp.usp.br/drupal/node/250. Acesso em: 13/11/2013.

LIMA, José Raimundo Oliveira. A economia popular e solidária como estratégia para o desenvolvimento local solidário. 2014 Tese (Doutorado em Educação e Contemporaneidade) - Faculdade de Educação, Programa de Pós-graduação em Educação e Contemporaneidade, Universidade do Estado da Bahia, Salvador, Bahia, 2014.

MANCE, Euclides André. A Revolução das redes: a colaboração solidária como uma alternativa pós-capitalista à globalização atual. 1. ed. Petrópolis: Vozes, 1999.

MARX, Karl. Para a crítica da Economia Política. Prefácio. Coleção Os Economistas. São Paulo: Abril Cultural, 1982. p. 23-27.

MIAILLE, Michel. Introdução crítica ao direito. 3. ed. Lisbo, Estampa, 2005.

NUNES, Débora. Incubação de empreendimentos de economia solidária: uma aplicação da pedagogia da participação. São Paulo: Annablume, 2009.

PASTORINI, Alejandra. A categoria “questão social” em debate. São Paulo: Cortez, 2004.

PITA, Flávia Almeida. A Sociedade empresária como instrumento de simulação em detrimento do crédito tributário e o parágrafo único do art. 116 do CTN. Revista Tributária e de Finanças Públicas, São Paulo, Revista dos Tribunais, n. 89, p. 126-159, nov./dez. 2009.

Relações entre o direito e a economia solidária no contexto brasileiro: reflexões a partir de uma experiência de incubação. XVII Congresso Brasileiro de Sociologia, GT07, Porto Alegre-RS, jul. $2015 . \quad$ Disponível em: http://automacaodeeventos.com.br/sociologia2015/sis/admin/pro_lista_programa.asp?st rConsultar=S. Acesso em: 10/09/2015. 
QUIJANO, Aníbal. Colonialidad y Modernidad-Racionalidad. In: BONILLA, Heraclio (Org.). Los conquistados: 1492 y la población indígena da las Américas. Santafé de Bogotá, Colombia: Tercer Mundo; Ecuador: FLACSO: Libri Mundi, 1992, p. 437-447.

. Colonialidade do poder, eurocentrismo e América Latina. In: LANDER, Edgardo (Org.) A colonialidade do saber: eurocentrismo e ciências sociais. Perspectivas latinoamericanas. Colección Sur Sur. Ciudad Autónoma de Buenos Aires, CLACSO, 2005.

. El Trabajo. Argumentos, México, D.F., v. 26, n. 72, p. 145-163, may-ago. 2013.

RÁO, Vicente. O direito e a vida dos direitos. v. 2. 4. ed. São Paulo: RT, 1997.

ROSEVICS, Larissa. Do pós-colonial à decolonialidade. Diálogos Internacionais. 28. nov. 2014. Disponível em: http://www.dialogosinternacionais.com.br/2014/11/do-pos-colonialdecolonialidade.html. Acesso em: 16/02/2016.

SANCHEZ, Fábio José Bechara. Além da informalidade, aquém dos direitos. 2012. Tese (Doutorado em Sociologia) Faculdade de Filosofia, Letras e Ciências Humanas da Universidade de São Paulo - USP - Departamento de Sociologia, São Paulo, 2012.

SANTOS, Boaventura de Souza (Org). Produzir para viver: os caminhos da produção não capitalista. Rio de Janeiro: Civilização Brasileira, 2005.

. Para além do pensamento abissal: das linhas globais a uma ecologia de saberes.

Novos Estudos - CEBRAP, São Paulo, n. 79, p. 71-94, nov. 2007.

. Poderá o direito ser emancipatório? Revista Crítica de Ciências Sociais, Coimbra,

n. 65, p. 3-76, mai. 2003. Disponível em:
www.ces.uc.pt/rccs/includes/download.php?id=817. Acesso em: 05/08/2014.

.Um discurso sobre as ciências. 7. ed. São Paulo: Cortez, 2010

SCHMIDT, Carlos. A economia solidária: panaceia do capitalismo pós-moderno ou um caminho para o socialismo. In: SCHMIDT, Carlos; NOVAES, Henrique T. Economia solidária e transformação social: rumo a uma sociedade para além do capital? Porto Alegre: Editora da UFRGS, 2013. p. 15-28.

SENAES.MTE. Sistema Nacional de Informações em Economia Solidária. Atlas digital da economia solidária: dados do segundo mapeamento nacional de empreendimentos econômicos solidários (EES), 2013. Disponível em: http://sies.ecosol.org.br/atlas. Acesso em: 10/08/2014.

- Sistema Nacional de Informações em Economia Solidária. Atlas da economia solidária no Brasil, 2007. Disponível em: http://consulta.mte.gov.br/atlas/AtlasES.html. Acesso em: 10/08/2014. 
. Avanços e desafios para as políticas públicas de economia solidária no Governo

Federal 2003/2010. Brasília, 2012. Disponível em:
http://acesso.mte.gov.br/data/files/8A7C812D3CB58904013CB5F52A404620/Oito\%20Ano s\%20da\%20SENAES.\%20Avan\%C3\%A7os\%20e\%20Desafios\%20para\%20as\%20PP\%20de\%2 OEconomia\%20Solid\%C3\%A1ria\%20no\%20Gov.\%20Federal\%202003_2010.pdf. Acesso em: 10/08/2014.

SILVA, Osmar Vieira da. Desconsideração da personalidade jurídica: aspectos processuais. Rio de Janeiro: Renovar, 2002.

SINGER, Paul. Introdução à economia solidária. São Paulo: Perseu Abramo, 2002.

SOMBRA, Laurenio. Identidade dos sujeitos: linguagem, constituição de sentido e valor.
Revista
Sísifo,
n. 1 ,
v. $\quad 1, \quad 2015$.
Disponível
em:

http://www.revistasisifo.com/2015/05/identidade-dos-sujeitos-linguagem_2.html Acesso em: 03/05/2015.

WEBER, Max. Conceitos básicos de sociologia. São Paulo: Centauro, 2005.

WOLKMER, Antonio Carlos. (2012) Una visión Crítica de la Cultura Jurídica en América latina. Revista El Foro. Colegio de Abogados. San José, Costa Rica, n. 12, pp. 13-19. Disponível em: http://dialnet.unirioja.es/servlet/articulo?codigo=4157314. Acesso em: 12/07/2015.

PITA ,Flávia Almeida. Formalização e economia popular solidária: o modelo de pessoa jurídica como sintoma da colonialidade do poder. RBSD - Revista Brasileira de Sociologia do Direito, v. 3., n. 1, p. 149-170, jan./abr. 2016.

Recebido em: 23/07/2016 Aprovado em: 30/07/2016 